\title{
Gap junctions and ovarian folliculogenesis
}

\author{
Gerald M. Kidder and Abdul Amir Mhawi* \\ Departments of Physiology, Obstetrics and Gynaecology, and Paediatrics, The University of \\ Western Ontario, London, Ontario N6A 5C1, Canada; and Child Health Research Institute, \\ 800 Commissioners Road East, London, Ontario N6C 2V5, Canada
}

\begin{abstract}
Gap junctions are collections of intercellular membrane channels that allow adjacent cells to share small molecules $(<1 \mathrm{kDa})$. Gap junction channels are composed of connexins, a homologous family of more than 20 proteins. In developing follicles, gap junctions couple the growing oocyte and its surrounding follicle cells into a functional syncytium. This review summarizes evidence on the expression of various connexins in developing follicles and the likely roles that some of the connexins play, on the basis of findings from gene targeting experiments in mice. Gap junctions between cumulus cells contain predominantly connexin43, and this connexin has also been detected using immunoelectron microscopy in a small minority of gap junctions at the oocyte surface. The importance of connexin43 for granulosa cell function is demonstrated by the fact that follicles lacking this connexin arrest in early preantral stages and produce incompetent oocytes. Connexin37 appears to be the only connexin contributed by oocytes to the gap junctions coupling them with granulosa cells, and loss of this connexin interferes with the development of antral follicles. The expression of multiple connexins in developing follicles is thus likely to reflect the multiple functions served by gap junctional communication in folliculogenesis.
\end{abstract}

Despite its structural simplicity, ovarian folliculogenesis requires complex regulatory mechanisms involving both extrinsic (endocrine) and intrinsic signalling pathways. In the case of intrinsic signalling pathways, numerous peptide 'intra-ovarian factors', which are members of several growth factor families, appear to influence follicle growth and maturation through paracrine signalling. Albertini et al. (2001) reviewed evidence that such signalling between developing oocytes and the surrounding granulosa cells is facilitated by transzonal projections from the granulosa cells that contact the oocyte surface. It is proposed that these contacts mediate local growth factor delivery and receptor occupation at the oocyte-granulosa cell interface. In the present review, another intraovarian signalling pathway, provided by gap junctions, is considered. Findings from gene expression studies in several species and gene targeting in mice have implicated gap junctional intercellular communication in follicular development and indicate its involvement in female infertility.

Gap junctions occur at sites of close cell apposition and are arrays of intercellular membrane channels that allow inorganic ions, second messengers, and small metabolites $(<1 \mathrm{kDa})$ to pass from cell to cell (for a review, see

Email gerald.kidder@fmd.uwo.ca

*Present address: Ontario Cancer Institute and Department of Medical Biophysics, University of Toronto, Toronto, Ontario M5G 2M9, Canada
Bruzzone et al., 1996a,b). The fundamental unit of the gap junction is the connexon, a cylindrical organelle that forms a hemichannel in the plasma membrane (Fig. 1). It is the end-to-end docking of connexons from two adjacent cells that creates the intercellular channel. Each connexon is a hexamer of protein subunits called connexins.

\section{The connexin family of gap junction proteins}

The connexins are members of a large family of integral membrane proteins, and each is the product of a distinct gene. There are 17 published rodent connexin sequences and more are in the process of being characterized (Bruzzone et al., 1996a,b; Dahl et al., 1996; Condorelli et al., 1998; Manthey et al., 1999; Söhl et al., 2001; Teubner et al., 2001). Connexins vary greatly in size: in rodents, for example, they range from connexin26 (Cx26), the smallest at $26 \mathrm{kDa}$, to connexin57 (Cx57), the largest at $57 \mathrm{kDa}$. All connexins have the same basic structure consisting of four membrane-spanning domains, two extracellular loops, a cytoplasmic loop, and cytoplasmic $\mathrm{N}$ - and C-termini. The extracellular loops form the contact domains that allow docking of connexons from adjacent cells. Sequence similarity among the family members is concentrated in the transmembrane domains and extracellular loops, whereas most of the sequence and length variation is in the cytoplasmic loops and C-terminal tails. This diversity is assumed to account for most of the distinct biophysical, permeability, 


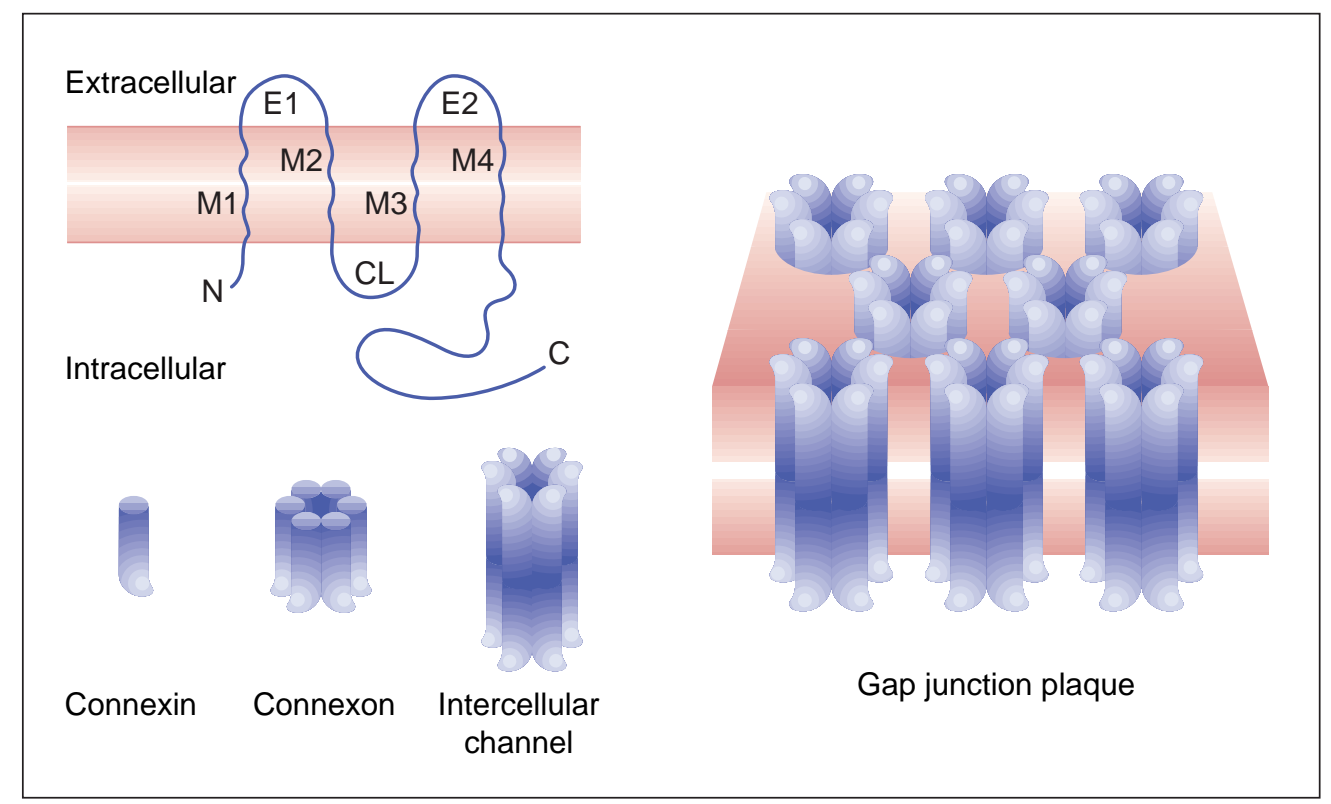

Fig. 1. Organization of connexins into connexons, intercellular channels, and gap junction plaques. CL: cytoplasmic loop domain; E1 and E2: extracellular domains 1 and 2, respectively; M1-4: membrane spanning domains 1-4. (From Kidder and Winterhager, 2001, with the permission of Frontiers in Bioscience (http://www.bioscience.org); modified from Simon and Goodenough, 1998.)

and regulatory properties exhibited by gap junction channels composed of different connexins (Bruzzone et al., $1996 a, b)$. For example, gap junction channels can be selective for different cyclic nucleotides and experimental tracer dyes, and are differentially sensitive to gating by protein kinases (Swenson et al., 1990; Bevans et al., 1998). Each connexin has a characteristic tissue distribution, although most organs (and even some individual cells) express more than one connexin (Bruzzone et al., 1996b). These facts support the hypothesis that channels formed of different connexins play distinctive roles. The potential diversity of types of channel generated by the diversity of connexins is further magnified by the existence of heterotypic channels, formed by the pairing of two homomeric connexons each composed of a different connexin, as well as heteromeric channels, in which the connexons comprise a mixture of two (or more) connexins (Bruzzone et al., 1996a,b; He et al., 1999). Given the different properties of the various connexins, this situation allows for great complexity with regard to the selectivity and regulation of intercellular coupling (He et al., 1999).

\section{Involvement of gap junctional coupling in development and reproduction}

Recent evidence indicates that gap junctional intercellular communication plays a variety of roles in mammalian development and reproduction. For example, the existence of 'communication compartments', distinct embryonic tissue domains delineated by restricted intercellular coupling
(Bruzzone et al., 1996a; Kidder and Winterhager, 2001), implies that gap junctions are involved in the control of cell differentiation. Indeed, in vitro differentiation models support this contention (Bani-Yaghoub et al., 1999a,b). Another established role for gap junctions is in the regulation of cell proliferation, including that of cancer cells (Zhu et al., 1991, 1992; Hellmann et al., 1999). There is even evidence that gap junctional coupling is required for cell migration during embryonic morphogenesis, such as in the case of the cardiac neural crest (for a review, see Lo et al., 1999). Definitive evidence that gap junctions play essential roles in organogenesis has come from connexin gene targeting experiments that have generated a variety of developmental and physiological abnormalities. Furthermore, there are now several human congenital abnormalities known to be associated with connexin mutations. Some of these abnormalities correlate with the mouse knockout phenotypes but others do not (for reviews, see White and Paul, 1999; Kelsell et al., 2001).

In addition, there is clear evidence of the involvement of gap junctions in the development of ovarian follicles. During the growth of mammalian oocytes, there is continuous coupling with the surrounding follicle cells via gap junctions (for reviews, see Eppig, 1991; Eppig et al., 1996). According to morphological evidence, this coupling begins as primordial follicles form and expands as folliculogenesis proceeds through primary, secondary and tertiary (antral) follicle stages (Mitchell and Burghardt, 1986). Amino acids, glucose metabolites and nucleotides are among the molecules known to be transferred to the growing oocyte through 
gap junctions (Eppig, 1991). In addition, signals that regulate meiotic maturation of the fully grown oocyte pass through the oocyte-granulosa cell gap junctions (Fagbohun and Downs, 1991; Coskun and Lin, 1994; Granot and Dekel, 1994; Downs, 1995). Although there is much still to be learned about the precise roles of gap junctions in folliculogenesis, oocyte growth, and oocyte maturation, the oocyte-granulosa cell complex remains one of the clearest examples of the involvement of gap junctional communication in a developmental process.

\section{Connexins in developing follicles}

Multiple connexins are expressed within the ovarian follicle, in some cases within the same cell type. For example, both Cx32 and Cx43 have been detected in gap junctions joining the cumulus granulosa cells of fully grown mouse follicles (Valdimarsson et al., 1993); the same two connexins are also present in rat granulosa cells ( $\mathrm{Li}$ and Mather, 1997). Cx43 (but not Cx32) gap junctions can be seen in what appear to be pre-granulosa cells as early as postnatal day 1 , when the first primordial follicles are forming (Juneja et al., 1999). Cx45 is present as a minor component in granulosa cell gap junctions of adult mice and rats, colocalizing with $\mathrm{Cx} 43$ in some gap junctions (Okuma et al., 1996; Alcoléa et al., 1999; Wright et al., 2001). For example, a freeze-fracture replica, immunogold labelled for Cx43 (5 nm particles) and Cx45 (15 nm particles) is shown (Fig. 2), demonstrating that Cx45 is restricted to small regions of some Cx43-containing gap junction plaques between cumulus cells (A. A. Mhawi, R. R. Shivers and G. M. Kidder, unpublished). A fourth ovarian connexin, $\mathrm{Cx37}$, is present from the primary follicle stage onward, restricted to the interface between oocytes and cumulus granulosa cells (Simon et al., 1997), although it should be noted that Wright et al. (2001) also detected some Cx37 immunoreactivity between granulosa cells in antral

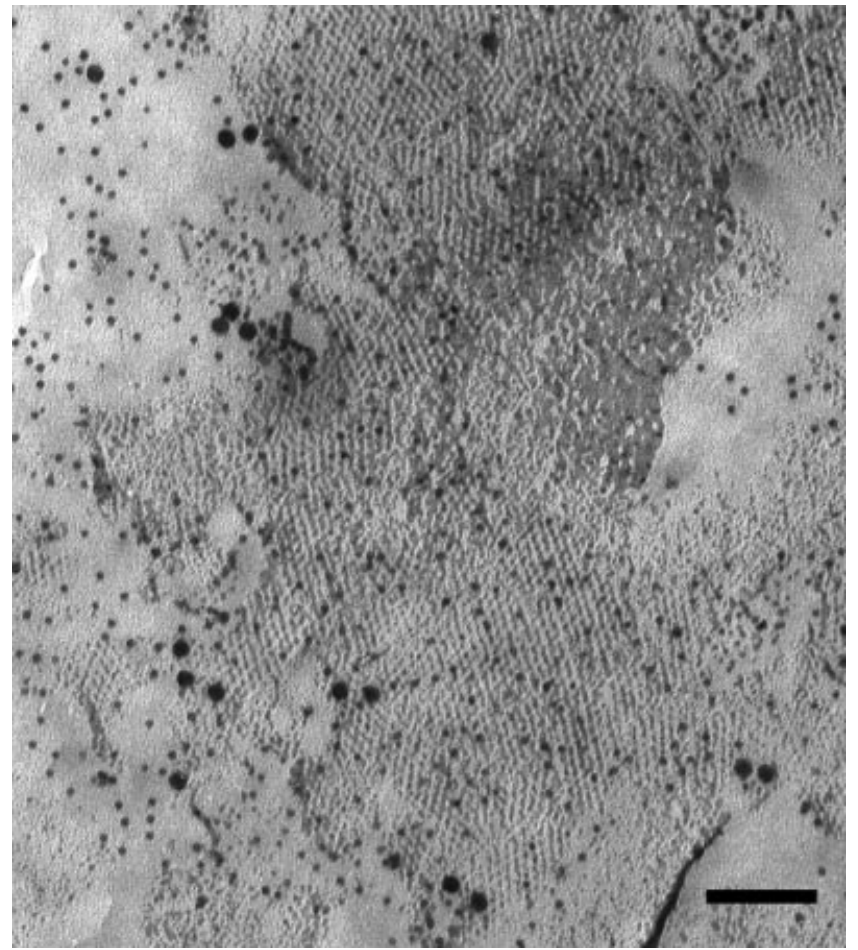

Fig. 2. Freeze-fracture replica prepared from cumulus granulosa cells of an adult mouse follicle immunogold labelled for connexin43 (Cx43) (5 nm particles) and Cx45 (15 nm particles). The distribution of gold particles indicates that $\mathrm{Cx} 45$ is restricted to small regions of some $\mathrm{Cx} 43$-containing gap junction plaques between cumulus cells. Unfixed mouse cumulus-oocyte complexes were slam frozen, fractured and replicated. Replicas were sequentially labelled with rabbit anti-Cx45 (overnight at $4{ }^{\circ} \mathrm{C}$ ) and mouse monoclonal anti-Cx43 ( $2 \mathrm{~h}$ at room temperature). The bound primary antibodies were visualized with gold-conjugated secondary antibodies (goat anti-rabbit and anti-mouse IgG, respectively). After immunolabelling, the replicas were fixed with $0.5 \%$ glutaraldehyde for $10 \mathrm{~min}$. Scale bar represents $150 \mathrm{~nm}$.

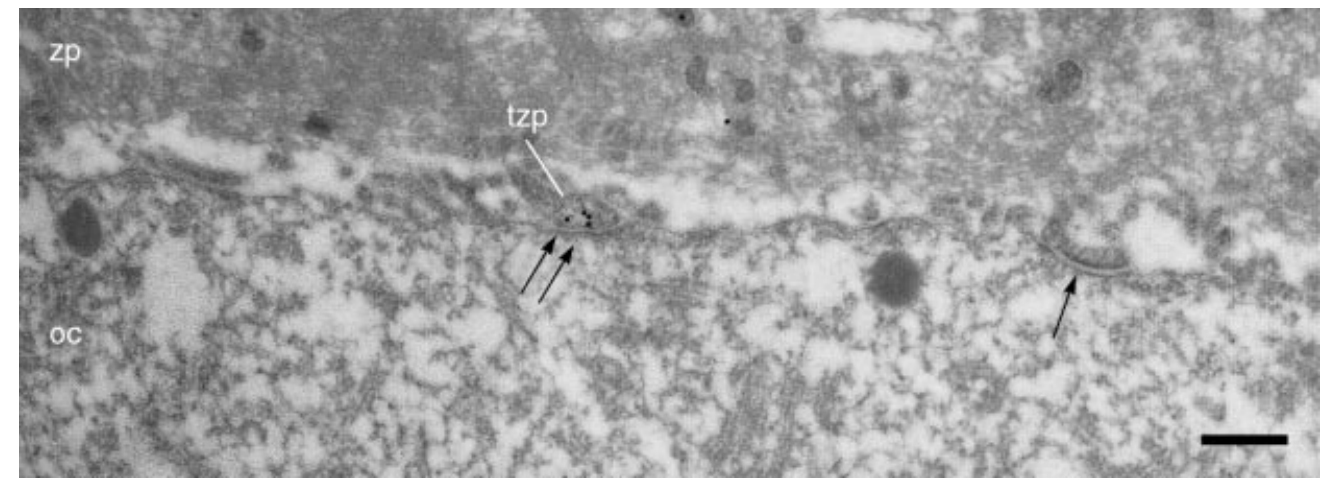

Fig. 3. Thin section taken through an adult mouse follicle immunogold labelled to reveal connexin43 (Cx43) in a gap junction at the oocyte surface (double arrow). Cx43 is restricted to the cumulus cell side of the junctional contact between the oocyte (oc) and a cumulus cell transzonal projection (tzp). Other junctional contacts on the oocyte surface were not labelled with the Cx43 antibody (single arrow). zp: zona pellucida. Pieces of ovary were fixed in $1 \%$ glutaraldehyde in phosphate buffer containing $0.1 \%$ $(\mathrm{w} / \mathrm{v})$ tannic acid. Thin sections were labelled with mouse anti-Cx43 for $2 \mathrm{~h}$ and the bound primary antibody was visualized with goat anti-mouse IgG conjugated to $15 \mathrm{~nm}$ gold particles. Scale bar represents $250 \mathrm{~nm}$. 


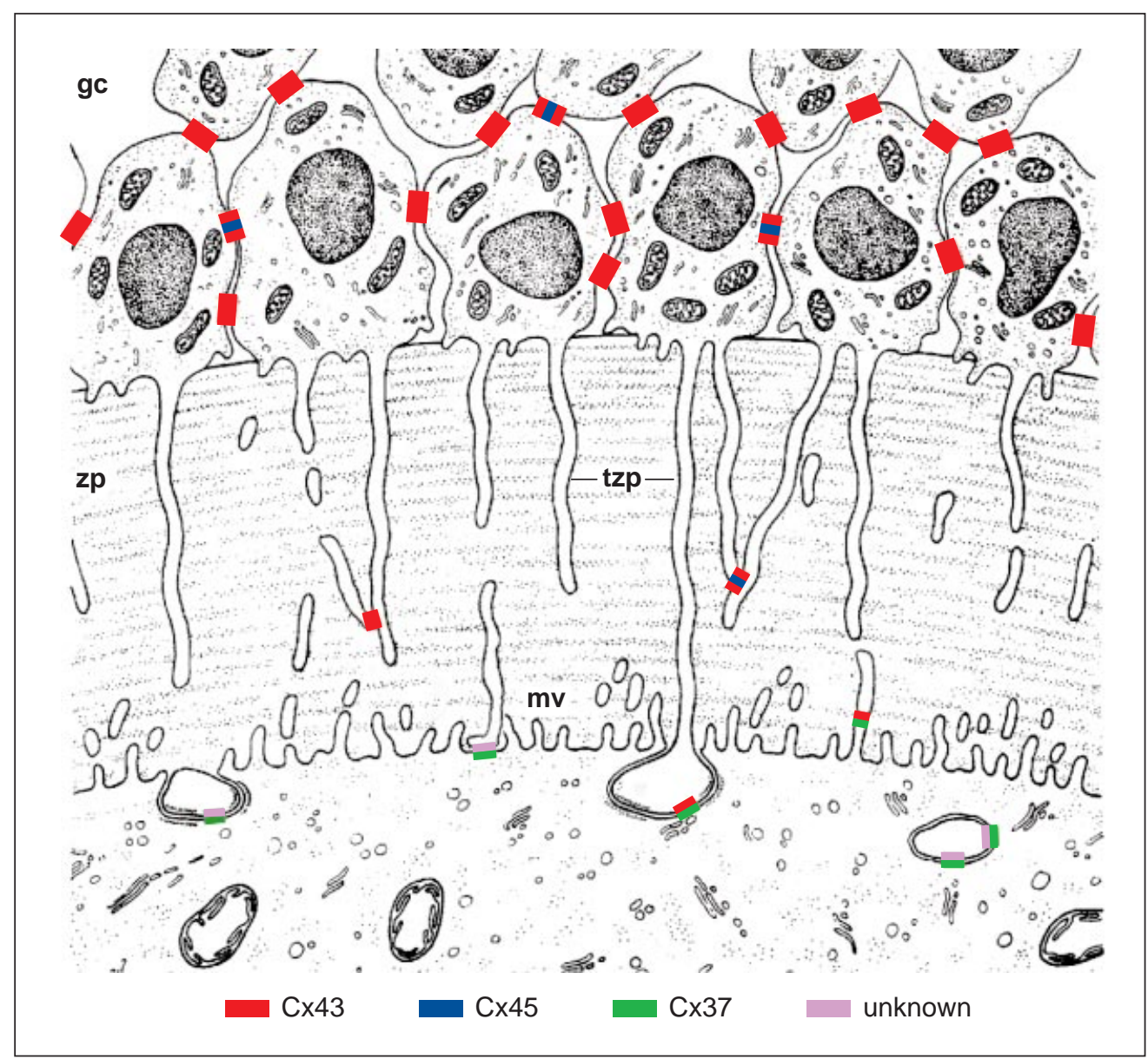

Fig. 4. Proposed distributions of connexin43 (Cx43), $C \times 45$, and $C \times 37$ in gap junctions of the mouse cumulus-oocyte complex on the basis of observations by immunoelectron microscopy. Cx37 is presumed to be the only gap junction protein contributed by the oocyte. In at least a few gap junctions at the surface of the oocyte (oc), Cx43 contributed by transzonal projections (tzp) from the cumulus granulosa cells (gc) docks with oocyte $\mathrm{C} \times 37$ to form heterotypic junctions. These junctional contacts can occur on oocyte microvilli (mv), flush with the oocyte surface, or in indentations of the oocyte plasma membrane. In other gap junctions at the oocyte surface, $\mathrm{C} \times 37$ from the oocyte docks with other cumulus cell connexins yet to be identified. Cx43 can be detected in all cumulus-cumulus gap junctions. Cx45 is a minor constituent of some gap junctions between cumulus cells and between their transzonal projections, but has not been detected in gap junctions at the oocyte surface. Additional connexins are known to be present in cumulus cells, but their distributions have not been determined at the ultrastructural level. zp: zona pellucida. (Adapted from Baker, 1982.)

follicles. A fifth connexin likely to play a role in folliculogenesis is Cx57 (Manthey et al., 1999), a mouse connexin, the gene for which is transcribed in several adult organs including the ovary. Cx57 is a homologue of Cx60, which was cloned from pig ovary cDNA (Itahana et al., 1998). Pig Cx60 is expressed in cumulus (but not mural) granulosa cells as well as in theca cells of the ovarian follicle. Although antibodies against $\mathrm{Cx} 57$ are not yet available, the presence of the mRNA encoding it in day 2 postnatal mouse ovaries has been confirmed by RT-PCR (K. J. Barr and G. M. Kidder, unpublished). Thus, in mice, connexins 32, 37, 43, 45 and 57 are all implicated in the process of folliculogenesis by virtue of their expression within developing or mature follicles, or in the case of $\mathrm{Cx} 57$, by virtue of the presence of the mRNA encoding it in ovaries containing only early stages of folliculogenesis. This list is probably not exhaustive, as other connexins have been detected in the ovarian follicles of other species, most notably Cx30.3 in pig and rat granulosa and theca cells (Itahana et al., 1996, 1998). In addition, Cx26 has been identified in sheep and cow oocytes and pig theca cells (Itahana et al., 1996; Grazul-Bilska et al., 1998; Johnson et al., 1999). According to Wright et al. (2001), Cx26 and Cx32 are also expressed in mouse oocytes and theca cells, but Cx26 mRNA was neither detected in denuded mouse oocytes or granulosa cells from juvenile ovaries by RT-PCR (G. M. Kidder and 
J. J. Eppig, unpublished) nor in adult rat ovaries by northern blotting (Risek et al., 1990). This discrepancy remains to be resolved. It is unlikely that $\mathrm{C} \times 32$ plays an important role in folliculogenesis because knockout mice lacking this connexin are fertile (Nelles et al., 1996).

Which connexins couple the oocyte with its companion cumulus cells? As noted above, immunofluorescence microscopy has been used to demonstrate that Cx37 occurs in gap junction-like structures on the surface of mouse oocytes, beneath the zona (Simon et al., 1997). In contrast, immunostaining and light microscopy do not convincingly reveal the presence of $\mathrm{C} \times 32$ or $\mathrm{Cx} 43$ in this location (Valdimarsson et al., 1993; Simon et al., 1997; Wright et al., 2001). However, under an electron microscope, both Cx43 and $\mathrm{Cx} 45$ have been detected in gap junctions close to the oocyte surface and, in the case of Cx43, on the cumulus cell side of gap junctions between cumulus cell projections and the oocyte plasma membrane (A. A. Mhawi, R. R. Shivers and G. M. Kidder, unpublished; Fig. 3). Thus, at least a few of the gap junctions connecting the oocyte with cumulus cells are heterotypic junctions formed from Cx37 (contributed by the oocyte) docking with $\mathrm{C} \times 43$ (contributed by the cumulus cell extensions). It is presumed that $\mathrm{C} \times 37$ is the only connexin contributed by the oocyte because ablation of this connexin by gene targeting removed all gap junctions from the oocyte surface (Simon et al., 1997). The identities of the other connexins docking with Cx37 at the oocyte surface remain to be determined. This information is summarized in Fig. 4.

\section{Roles of gap junctional intercellular communication in folliculogenesis}

Connexin knockout mice have begun to provide new insights into the roles of gap junctions in ovarian development and folliculogenesis. Mice lacking Cx37 as a result of a targeted disruption of the Gja4 gene are viable and ovarian folliculogenesis proceeds in apparently normal fashion until the late preantral stage (Fig. 5; Simon et al., 1997; Carabatsos et al., 2000). Mature Graafian follicles never develop, and ovulation cannot be induced by gonadotrophin stimulation. The mutation abolishes intercellular coupling between cumulus cells and oocytes and, consistent with the role of cumulus-oocyte coupling in transferring nutrients to the oocyte, causes oocyte growth to arrest at $74 \%$ of normal size (Carabatsos et al., 2000). In addition, oocytes developing without Cx37 fail to achieve full meiotic competence. Eventually, the mutant ovaries become filled with structures resembling corpora lutea, as though the granulosa cells have differentiated prematurely as luteal cells (Simon et al., 1997). It is possible that gap junctional coupling between oocytes and granulosa cells via $\mathrm{C} \times 37$ channels is required to maintain the differentiated state of the granulosa cells by preventing them from luteinizing before ovulation.

A very different result was obtained when Gja1, the gene encoding Cx43, was ablated by gene targeting. Offspring

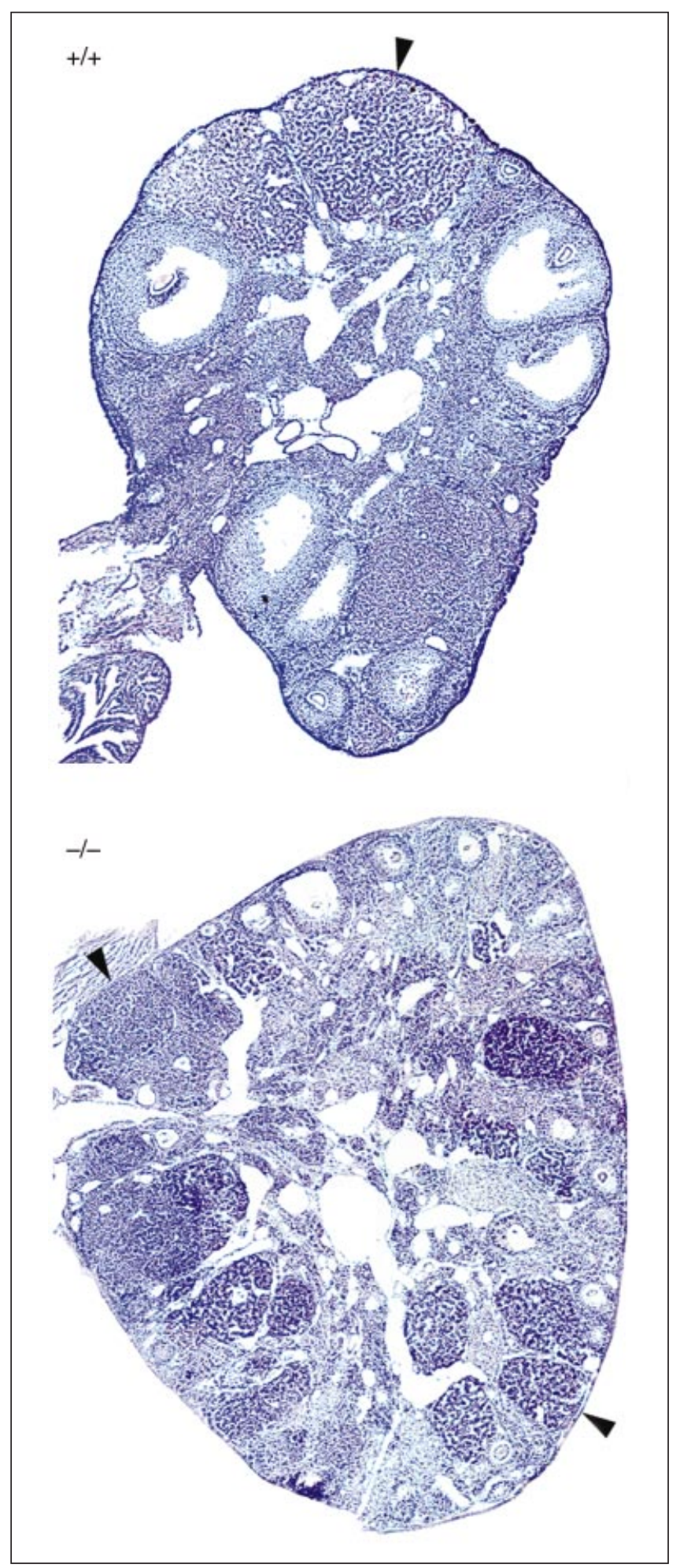

Fig. 5. Abnormal folliculogenesis in connexin37 (Cx37) knockout mice. Graafian follicles are present in ovaries from 4-month-old wildtype females $(+/+)$ but not in ovaries from mutant females of the same age $(-/-)$. Instead, the mutant ovaries become filled with numerous structures resembling small corpora lutea (arrowheads). An authentic corpus luteum is indicated in the wild-type ovary. (Reprinted from Simon et al., 1997, copyright 1997 Macmillan Magazines Ltd.) 

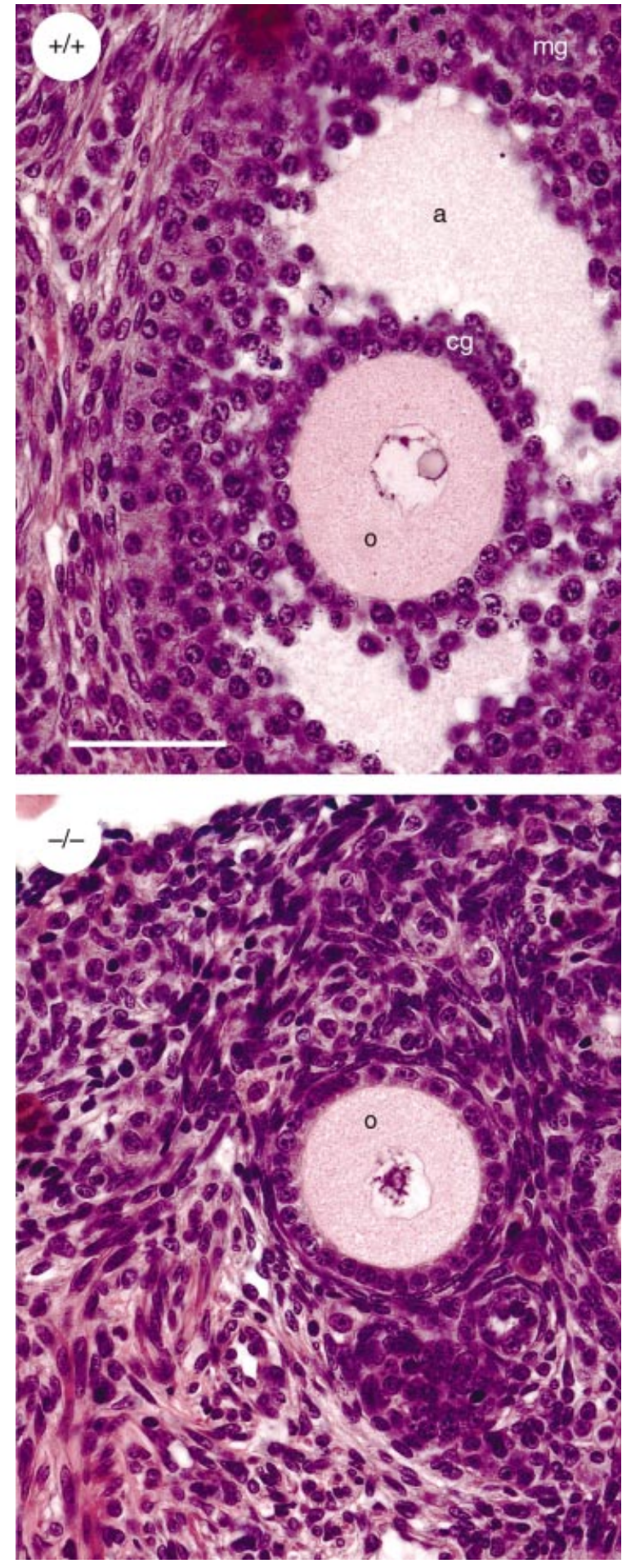

Fig. 6. Abnormal folliculogenesis in connexin43 (Cx43) knockout ovaries. Ovaries from late gestation fetuses lacking Cx43 were grafted into the kidneys of immunocompromised adult female hosts and recovered after 3 weeks. Ovaries from wild-type fetuses were similarly grafted to serve as controls. In the absence of Cx43 $(-/-)$, follicular development arrests in an early preantral stage reflecting the failure of the granulosa cell population to expand. However, grafted wild-type ovaries contain antral follicles of normal appearance (+/+). a: antrum; cg: cumulus granulosa layer; (either male or female) homozygous for the mutation have very few germ line cells (Juneja et al., 1999), which is evident from as early as 11.5 days after mating, when the first primordial germ cells (PGCs) have taken up residence in the genital ridges, indicating that the deficiency arises during the period of PGC migration. However, the gonads of $\mathrm{Gja}^{-/-}$fetuses do contain about $10 \%$ of the normal number of germ cells. Therefore, it was of interest to determine whether the few oocytes in the ovaries of Gja $1^{-1-}$ neonates could participate in folliculogenesis. As the absence of Cx43 is associated with neonatal lethality, which is the result of a severe heart defect (Reaume et al., 1995), and because ovarian folliculogenesis in mice is a postnatal process, it was necessary to devise artificial means of studying folliculogenesis in the Cx43 knockout. First, neonatal ovaries were cultured in vitro, revealing that postnatal folliculogenesis is retarded, if not arrested, in the absence of Cx43 (Juneja et al., 1999). Second, neonatal ovaries were grafted into the kidney capsules of ovariectomized, immunocompromised adult mice for postnatal development for up to 3 weeks (Ackert et al., 2001). In this location, grafted wild-type ovaries developed a full range of follicles from primordial through to large, antral follicles (Fig. 6). However, folliculogenesis in mutant follicles arrested in most cases before the follicles had become multilaminar, indicating that coupling among granulosa cells via Cx43 channels is required to sustain granulosa cell proliferation. Failure of the Cx43-deficient follicles to develop multiple layers of granulosa cells was correlated with reduced growth of the oocytes. Oocytes were morphologically abnormal, meiotically incompetent, and could not be fertilized. The inability of granulosa cells to proliferate in the absence of $\mathrm{Cx} 43$ is consistent with the presence of this connexin from the onset of folliculogenesis and implies either that Cx43 is the only connexin expressed in granulosa cells of primary follicles or that it plays an indispensable role that cannot be fulfilled by other connexins that might be present.

\section{Conclusions}

Ovarian folliculogenesis and the production of fertilizable oocytes depend on gap junctional intercellular communication within both the developing and the mature follicle. Many connexins, including but probably not limited to Cx26, Cx30.3, Cx32, Cx37, Cx40, Cx43, Cx45 and Cx57, are expressed within the oocyte-granulosa cell complex depending on the species, but it is not yet clear whether each has an essential role to play (Cx32 clearly does not in mice). The different phenotypes of $\mathrm{Gja}^{-1_{-}^{-}}$and $\mathrm{Gja}^{-{ }^{--}}$mice indicate that Cx43 and Cx37, at least, do play distinct and essential roles consistent with the immunolocalization data showing Cx43 in granulosa cells and transzonal projections

mg, mural granulosa layer; o: oocyte. (Reprinted by permission from Ackert et al., 2001, copyright 2001 Academic Press.) 
from the granulosa cells to the oocyte, and Cx37 restricted to gap junctions at the oocyte surface. Because channels composed of these two connexins have different permeability properties, it is possible that molecules passing through the heterologous gap junctions at the oocyte surface, some of which appear to be heterotypic, are different from those passing through gap junctions between granulosa cells. Identification of those molecules and elucidation of their physiological functions within the follicle must be research priorities of the future.

Work from the authors' laboratory cited in this review was funded by the Canadian Institutes of Health Research. We thank Dale Laird and Daniel Gros for supplying primary antibodies and Alex Simon for providing the micrographs of Fig. 5. We are especially grateful to Richard Shivers for sharing his expertise in freeze-fracture.

\section{References}

Key references are identified by asterisks.

*Ackert CL, Gittens JEI, O'Brien MJ, Eppig JJ and Kidder GM (2001) Intercellular communication via connexin43 gap junctions is required for ovarian folliculogenesis in the mouse Developmental Biology 233 $258-270$

Albertini DF, Combelles CMH, Benecchi E and Carabatsos MJ (2001) Cellular basis for paracrine regulation of ovarian follicle development Reproduction 121 647-653

Alcoléa S, Théveniau-Ruissy M, Jarry-Guichard T et al. (1999) Downregulation of connexin 45 gene products during mouse heart development Circulation Research 84 1365-1379

Baker TG (1982) Oogenesis and ovulation. In Reproduction in Mammals 1. Germ Cells and Fertilization pp 17-45 Eds CR Austin and RV Short. Cambridge University Press, Cambridge

Bani-Yaghoub M, Underhill TM and Naus CCG (1999a) Gap junction blockage interferes with neuronal and astroglial differentiation of mouse P19 embryonal carcinoma cells Developmental Genetics 24 69-81

Bani-Yaghoub M, Bechberger JF, Underhill TM and Naus CCG (1999b) The effects of gap junction blockage on neuronal differentiation of human NTera2/clone D1 cells Experimental Neurology 156 16-32

Bevans CG, Kordel M, Rhee SK and Harris AL (1998) Isoform composition of connexin channels determines selectivity among second messengers and uncharged molecules Journal of Biological Chemistry 273 2808-2816

Bruzzone R, White TW and Goodenough DA (1996a) The cellular internet: on-line with connexins BioEssays 18 709-718

Bruzzone R, White TW and Paul DL (1996b) Connections with connexins: the molecular basis of direct intercellular signaling European Journal of Biochemistry 238 1-27

*Carabatsos MJ, Sellitto C, Goodenough DA and Albertini DF (2000) Oocyte-granulosa cell heterologous gap junctions are required for the coordination of nuclear and cytoplasmic meiotic competence Developmental Biology 226 167-179

Condorelli DF, Parenti R, Spinella F, Salinaro AT, Belluardo N, Cardile V and Cicirata F (1998) Cloning of a new gap junction gene (Cx36) highly expressed in mammalian brain neurons European Journal of Neuroscience 10 1202-1208

Coskun S and Lin YC (1994) Effects of transforming growth factors and activin-A on in vitro porcine oocyte maturation Molecular Reproduction and Development 38 153-159

Dahl E, Manthey D, Chen Y, Schwarz H-J, Chang YS, Lalley PA, Nicholson BJ and Willecke K (1996) Molecular cloning and functional expression of mouse connexin-30, a gap junction gene highly expressed in adult brain and skin Journal of Biological Chemistry 271 17 903-17910

Downs SM (1995) The influence of glucose, cumulus cells, and metabolic coupling on ATP levels and meiotic control in the isolated mouse oocyte Developmental Biology $167502-512$

Eppig JJ (199l) Intercommunication between mammalian oocytes and companion follicle cells BioEssays 13 569-574

Eppig JJ, O'Brien M and Wigglesworth K (1996) Mammalian oocyte growth and development in vitro. Molecular Reproduction and Development 44 260-273

Fagbohun CF and Downs SM (1991) Metabolic coupling and ligandstimulated meiotic maturation in the mouse cumulus-oocyte complex Biology of Reproduction 45 851-859

Granot I and Dekel N (1994) Phosphorylation and expression of connexin43 ovarian gap junction protein are regulated by luteinizing hormone Journal of Biological Chemistry $26930502-30509$

Grazul-Bilska AT, Redmer DA, Bilski JJ, Jablonka-Shariff A, Doraiswamy V and Reynolds LP (1998) Gap junctional proteins, connexin 26, 32, and 43 in sheep ovaries throughout the estrous cycle Endocrine 8 269-279

He DS, Jiang JX, Taffet SM and Burt JM (1999) Formation of heteromeric gap junction channels by connexins 40 and 43 in vascular smooth muscle cells Proceedings of the National Academy of Sciences USA 96 6495-6500

Hellmann P, Grümmer R, Schirrmacher K, Rook $M$, Traub $O$ and Winterhager E (1999) Transfection with different connexin genes alters growth and differentiation of human choriocarcinoma cells Experimental Cell Research 246 480-490

Itahana K, Morikazu Y and Takeya T (1996) Differential expression of four connexin genes, Cx-26, Cx-303, Cx32, and Cx43, in the porcine ovarian follicle Endocrinology 137 5036-5044

Itahana K, Tanaka T, Morikazu Y, Komatu S, Ishida N and Takeya T (1998) Isolation and characterization of a novel connexin gene, Cx-60, in porcine ovarian follicles Endocrinology 139, 320-329

Johnson ML, Redmer DA, Reynolds LP and Grazul-Bilska AT (1999) Expression of gap junctional proteins connexin 43, 32, and 26 throughout follicular development and atresia in cows Endocrine 10 43-51

Juneja SC, Barr KJ, Enders GC and Kidder GM (1999) Defects in the germ line and gonads of mice lacking connexin43 Biology of Reproduction 60 1263-1270

Kelsell DP, Dunlop J and Hodgins MB (2001) Human diseases: clues to cracking the connexin code? Trends in Cell Biology 11 2-6

Kidder GM and Winterhager E (2001) Intercellular communication in preimplantation development: the role of gap junctions Frontiers in Bioscience 6 d731-d736 (http://wwwbioscienceorg/2001/v6/d/kidder/ fulltexthtm)

Li R and Mather JP (1997) Lindane, an inhibitor of gap junction formation, abolishes oocyte directed follicle organizing activity in vitro. Endocrinology 138 4477-4480

Lo CW, Waldo KL and Kirby ML (1999) Gap junction communication and the modulation of cardiac neural crest cells Trends in Cardiovascular Medicine 963-69

Manthey D, Bukauskas F, Lee CG, Kozak CA and Willecke K (1999) Molecular cloning and functional expression of the mouse gap junction gene connexin57 in human HeLa cells Journal of Biological Chemistry $27414716-14723$

Mitchell PA and Burghardt RC (1986) The ontogeny of nexuses (gap junctions) in the ovary of the fetal mouse Anatomical Record 214 283-288

Nelles E, Bützler C, Jung D et al. (1996) Defective propagation of signals generated by sympathetic nerve stimulation in the liver of connexin32deficient mice Proceedings of the National Academy of Sciences USA 93 9565-9570

Okuma A, Kuraoka A, lida H, Inai T, Wasano K and Shibata Y (1996) Colocalization of connexin 43 and connexin45 but absence of connexin40 in granulosa cell gap junctions of rat ovary Journal of Reproduction and Fertility 107 255-264

Reaume A, De Sousa PA, Kulkarni S, Langille BL, Zhu D, Davies TC, Juneja SC, Kidder GM and Rossant J (1995) Cardiac malformation in neonatal mice lacking connexin43 Science 267 1831-1834

Risek B, Guthrie S, Kumar NM and Gilula NB (1990) Modulation of gap junction transcript and protein expression during pregnancy in the rat Journal of Cell Biology 110 269-282 
Simon AM and Goodenough DA (1998) Diverse functions of vertebrate gap junctions Trends in Cell Biology 8 477-483

*Simon AM, Goodenough DA, Li E and Paul DL (1997) Female infertility in mice lacking connexin37 Nature 385 525-529

Söhl G, Eiberger J, Jung YT, Kozak CA and Willecke K (2001) The mouse gap junction gene connexin29 is highly expressed in sciatic nerve and regulated during brain development Biological Chemistry 382 973-978

Swenson KI, Piwnica-Worms H, McNamee H and Paul DL (1990) Tyrosine phosphorylation of the gap junction protein connexin43 is required for

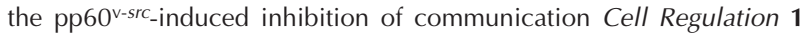
989-1002

Teubner B, Odermatt B, Güldenagel M et al. (2001) Functional expression of the new gap junction gene connexin47 transcribed in mouse brain and spinal cord neurons Journal of Neuroscience 21 1117-1126

Valdimarsson G, De Sousa PA and Kidder GM (1993) Coexpression of gap junction proteins in the cumulus-oocyte complex Molecular Reproduction and Development 36 7-15

*White TW and Paul DL (1999) Genetic diseases and gene knockouts reveal diverse connexin functions Annual Review of Physiology 61 283-310

*Wright CS, Becker DL, Lin JS, Warner AE and Hardy K (2001) Stagespecific and differential expression of gap junctions in the mouse ovary: connexin-specific roles in follicular regulation Reproduction 121 77-88

Zhu D, Caveney S, Kidder GM and Naus CCG (1991) Transfection of C6 glioma cells with connexin43 cDNA: analysis of expression, intercellular coupling, and cell proliferation Proceedings of the National Academy of Sciences USA 88 1883-1887

Zhu D, Kidder GM, Caveney S and Naus CCG (1992) Growth retardation in glioma cells cocultured with cells overexpressing a gap junction protein Proceedings of the National Academy of Sciences USA $\mathbf{8 9}$ $10218-10221$ 